\title{
AVALIAÇÃO MICROBIOLÓGICA DE UM PROCESSO DE SANIFICAÇÃO DE GALÕES DE ÁGUA COM A UTILIZAÇÃo DO OZÔNIO ${ }^{1}$
}

\author{
Claudia Catelani CARDOSO${ }^{2}$, Sandra Maria Oliveira Morais VEIGA ${ }^{3, *}$, \\ Luiz Carlos do NASCIMENTO ${ }^{4}$, João Evangelista FIORINI ${ }^{4}$, Luiz Augusto do AMARAL 5
}

\begin{abstract}
RESUMO
O Brasil é o sétimo maior consumidor mundial de águas engarrafadas. Os recipientes mais utilizados, galões plásticos de 20 litros, devem ser submetidos à inspeção individual e posteriormente a sanificação. Recentemente, enfermidades associadas a microrganismos emergentes têm despertado o interesse por novos sanitizantes. Entre estes, o gás ozônio é um dos mais atraentes em virtude da sua segurança e eficácia superiores aos desinfetantes convencionais, não gerando resíduos tóxicos. Neste trabalho, o ozônio foi avaliado como método alternativo na sanificação de galões de água de 20 litros, na cidade de Alfenas, MG. Trinta galões foram avaliados sem tratamento e trinta após a sanificação com água ozonizada $(4 \mathrm{mg} / \mathrm{L} / 2$ minutos) quanto à contagem total de microrganismos aeróbios mesófilos heterotróficos, número mais provável (NMP) de coliformes totais e Escherichia coli, Staphyloccocus aureus e Pseudomonas spp. em 100mL de solução enxaguatória. A contagem média de unidades formadoras de colônias (UFC) de microrganismos heterotróficos no estágio de pré-lavagem foi de $5,7 / \mathrm{cm}^{2}$ enquanto que o tratamento com a água ozonizada reduziu este valor para $0,003 / \mathrm{cm}^{2}$, além de promover a negativação das análises para coliformes Pseudomonas ssp. e somente 13,3\% das amostras apresentaram-se positivas para Staphylococcus aureus após a sanificação. Concluiu-se que o tratamento com utilização de ozônio foi eficiente, nas condições testadas.

Palavras-chave: ozônio; águas minerais - embalagens; desinfecção e desinfetantes.
\end{abstract}

\section{SUMMARY}

MICROBIOLOGICAL EVALUATION OF A MINERAL WATER PACKAGING SANITIZING PROCESSING WITH OZONE. Brazil is ranked as the seventh in worldwide consumer of bottled mineral water. The mineral water bottles should be inspected regarding the physical integrity and then submitted to sanitization, using specific wash machines. Recently diseases associated with new microbial strains have increased interest in exploring different disinfectants in food sanitizing processing. Ozone is particularly attractive because of its high security and effectiveness than conventional disinfectants, without risk of toxic residues generating. The current work evaluated the ozone as an alternative method for sanitizing 20 liters mineral water gallons in Alfenas-MG (Brazil). Thirty gallons were analyzed before (pre-wash) and thirty after washing with ozonated water $(4 \mathrm{mg} / \mathrm{L}, 2 \mathrm{~min}$.) (post-wash). The samples were evaluated regarding the number of aerobic mesophiles, Escherichia coli, total coliforms, Staphylococcus aureus and Pseudomonas spp. The data about the aerobic mesophiles at pre-wash was 5,7 colony forming units $/ \mathrm{cm}^{2}$ and post-wash was $0,003 \mathrm{CFU} / \mathrm{cm}^{2}$. The post-wash samples showed negative of total coliforms, E. coli and Pseudomonas spp. and only 13,3\% samples presented grow of $S$. aureus. In comparison, all the pre-wash showed presence of total coliforms and S. aureus. E. coli and Pseudomonas spp. were present in $80 \%$ and $50 \%$ of the samples, respectively. Therefore, the sanitizing processing with ozone $(4 \mathrm{mg} / \mathrm{L})$ was demonstrated in this study was an adequate alternative method for washing mineral water gallons in tested condition.

Keywords: ozone; mineral water - package; disinfection and disinfectants.

\section{1 - INTRODUÇÃO}

O Brasil, sétimo maior consumidor de águas engarrafadas no mundo, consumiu, em 1999, três milhões de litros, segundo o Departamento Nacional de Produção Mineral (DNPM) [7]. Este mercado está em crescimento, condicionado pela insatisfação da população com a água dos sistemas públicos de abastecimento e à proliferação de redes de distribuição que popularizaram a utilização dos garrafões de 20 litros.

A água mineral natural deve apresentar qualidade que garanta ausência de risco à saúde do consumidor, devendo ser captada, processada e envasada obedecendo às condições higiênico-sanitárias e as boas práticas de fabricação. As operações de captação, adução, elevação mecânica, armazenamento, filtração, envase, adi-

\footnotetext{
1. Recebido para publicação em 02/05/2001. Aceito para publicação em 07/05/2002.

2. Centro de Estudos do Ozônio, UNIFENAS, Alfenas, MG.

3. Depto. de Farmácia, EFOA, R. Gabriel Monteiro da Silva, 714, CEP 37130.000 - Alfenas, MG.veiga@int.efoa.br

4. Depto. de Biologia, UNIFENAS, Alfenas, MG.

5. Depto. de Medicina Preventiva, UNESP, Jaboticabal, SP.

* A quem a correspondência deve ser enviada.
}

ção de $\mathrm{CO}_{2}$, transporte e manuseio não devem alterar a composição original [5].

A integridade fisica de embalagens utilizadas para o envase de água mineral deverá sofrer inspeção individual, seguida de sanificação em lavadoras específicas que devem localizar-se o mais próximo da sala de envase.

A sanitização deve ser realizada por meios físicos ou químicos empregando-se procedimentos de eficácia comprovada. Na sanitização por meios físicos emprega-se calor (vapor; água quente) e radiação ultravioleta [9], enquanto que a sanitização através de agentes químicos depende de uma série de compostos bactericidas, desde ácidos orgânicos até agentes umectantes complexos. Por questões econômicas, na prática os compostos clorados, iodados e os quaternários de amônia são os mais utilizados [1].

A sanificação inadequada das embalagens ou a sua contaminação posterior, resulta na condenação do lote de água mineral. Segundo o Ministério da Saúde, neste produto não podem ser constatadas as presenças de $E$. coli ou coliformes (fecais) termotolerantes ou coliformes totais, enterococos, $P$. aeruginosa e/ou clostrídios sulfito redutores, em quantidade superior a $2 \mathrm{UFC} / \mathrm{mL}[5]$. 
Recentes enfermidades associadas aos microrganismos emergentes como a Listeria monocytogenes, Campylobacter jejuni, Salmonella e cepas virulentas de E. coli (sorotipo O157:H7) vem despertando o interesse por novos processos de sanitização na indústria de alimentos, devido à constatação de resistência aos desinfetantes rotineiros [12].

Numerosos compostos químicos utilizados na desinfecção provocam efeitos mutagênicos, com perigos referentes a resíduos potencialmente carcinogênicos nos alimentos ou embalagens[6].

O gás ozônio apresenta certas características sanitizantes atraentes para a indústria alimentícia, por ser mais seguro e potente do que os desinfetantes convencionais, agir sobre um grande número de microrganismos, incluindo patógenos resistentes. Além de ser reconhecido como seguro para o tratamento de garrafas de água ("General Recognized As Safe"-GRAS) pela "Food and Drug Administration" americana, ser utilizado efetivamente no tratamento da água para o consumo na Europa há mais de cem anos e na indústria de alimentos por décadas, o ozônio não deixa resíduos tóxicos nos alimentos [14], capazes de alterarem o odor e o sabor dos mesmos.

Quimicamente o ozônio, arranjo molecular triatômico e instável do oxigênio, pode ser gerado pela excitação do oxigênio molecular a oxigênio atômico, em um ambiente energizado que permite a recombinação de átomos. É um potente agente oxidante, com um potencial de oxiredução de 2,07V [4]. À temperatura ambiente é um gás de coloração azulada porém nas concentrações utilizadas com propósitos de desinfecção, torna-se incolor [11].

O objetivo desse trabalho foi avaliar a eficiência da utilização do ozônio como método alternativo na sanificação de galões de água de 20 litros.

\section{2 - MATERIAIS E MÉTODO}

\section{1 - Amostras}

Um total de sessenta galões de 20 litros de água mineral na região de Alfenas, MG, oriundos de um mesmo distribuidor foi escolhido aleatoriamente. A experiência consistiu na análise comparativa entre 30 galões sem tratamento e outros 30 após a lavagem e desinfecção com água ozonizada a $4 \mathrm{mg} / \mathrm{L}$, durante 2 minutos. O processo foi realizado em um protótipo de micro-estação de lavagem.

\section{2 - Amostragem}

As amostras foram coletadas procedendo-se o enxágüe do galão com $1000 \mathrm{~mL}$ de solução salina esterilizada. Durante a mesma, o galão foi agitado mecanicamente durante 30seg. sendo que, para cada amostragem, utilizou-se uma luva de látex esterilizada para obstruir a boca do galão. A seguir a solução enxaguatória foi recuperada e acondicionada em recipiente esterilizado e transportada ao Laboratório, em caixa térmica com gelo, para ser imediatamente processada.

\section{3 - Análises microbiológicas}

As amostras foram avaliadas quanto à contagem total de microrganismos aeróbios mesófilos heterotróficos e ao número mais provável (NMP) de coliformes totais e E.coli, utilizando-se os testes "SimPlate" e "Colilert" (IDEXX $\left.{ }^{\circledR}\right)$, respectivamente, sendo que ambos os testes utilizam a metodologia do substrato cromogênico definido. Inoculou-se $1,0 \mathrm{~mL}$ da solução enxaguatória no SimPlate enquanto que $100 \mathrm{~mL}$ da mesma solução foram destinados ao teste Colilert, segundo as especificações do fabricante. As placas do SimPlate firam incubadas a $35,5^{\circ} \mathrm{C}$ por 48 horas e as cartelas do Colilert foram incubadas a mesma temepratura por 24-28 horas, sendo que as amostras positivas para coliformes totais foram também analisadas para a contagem de coliformes fecais, utilizando-se uma lâmpada ultravioleta com comprimento de onda $365 \mathrm{~nm}$.

Além destas espécies, as amostras foram avaliadas quanto à presença de S. aureus e Pseudomonas spp., utilizando-se $100 \mathrm{~mL}$ da solução enxaguatória. Após a homogeneização da solução, procedeu-se a filtragem de duas frações de $100 \mathrm{~mL}$, através de um sistema de filtração a vácuo e membrana de celulose com porosidade de $0,47 \mu \mathrm{m}$ de diâmetro; uma membrana foi então acoplada em Âgar Cetrimide (Pseudomonas spp.) e a outra em Agar Baird Parker (S. aureus). Ambas placas foram incubadas a $35,5^{\circ} \mathrm{C}$ por $24-28$ horas.

\section{4 - Tratamento}

Os galões sofreram a lavagem, utilizando-se água e tensoativo não-iônico do tipo álcool etoxilado, na dose de 0,4mL/L (Liquid Force-Ecolab ${ }^{\circledR}$ ), durante $2 \mathrm{~min}$., em seguida, de um enxágüe de $2 \mathrm{~min}$., com a solução desinfetante $(4 \mathrm{mg} / \mathrm{L}$ de ozônio dissolvido). Os galões foram mantidos na posição invertida, por 1 minuto, antes da coleta das amostras.

A micro-estação operou com duas bombas: uma para a concentração do gás e outra para a pulverização, utilizando o gerador, (modelo EAS 380 DC), com capacidade de $8 \mathrm{~g} /$ hora. Para a pulverização utilizou-se bico em aço inoxidável (Spray System $®$ ), sendo que o resíduo de ozônio durante a desinfecção foi monitorado continuamente por um monitor (modelo SL 7685, B\&C eletronics).

\section{5 - Avaliação da superfície interna}

A área interna do galão foi calculada da seguinte forma:

Área interna $=2 A_{1}+A_{2}$

onde,

$A_{1}=\frac{\pi \cdot D^{2}}{4}$

onde D (diâmetro da base do galão) $=25 \mathrm{~cm}$ 
e $A_{2}=2 \pi R x h \ldots R=\frac{D}{2}$

onde $\mathrm{h}$ (altura) $=35 \mathrm{~cm}$

Área interna $=3730,7 \mathrm{~cm}^{2}$

\section{3 - RESULTADOS E DISCUSSÃO}

A American Public Health Association [2] considera os equipamentos e utensílios satisfatoriamente limpos e sanificados, quando não apresentarem contagens superiores a 2 aeróbios mesófilos $/ \mathrm{cm}^{2}$ [13] sendo este valor considerado rígido para a realidade brasileira [3]. PELCZAR, CHAN, KRIEG [8] sugerem três Reduções Decimais $(\mathrm{RD})$ como resultado satisfatório, não mencionando o tempo de exposição.

Na Tabela 1 verifica-se que o número médio de bactérias mesófilas heterotróficas foi de $21,6 \mathrm{UFC} / \mathrm{mL}$ na prélavagem. Considerando que o volume da solução enxaguatória era de $1.000 \mathrm{~mL}$, o número total de bactérias heterotróficas para a área interna do galão na prélavagem foi de $2,2 \times 10^{4} \mathrm{UFC} / \mathrm{L}$ e no pós-lavagem foi igual a $1,3 \times$ UFC/L. Tendo em vista que á área interna do galão seja de aproximadamente $3.730,7 \mathrm{~cm}^{2}$ [15], o número médio de mesófilos dos galões sem tratamento foi de $5,7 \mathrm{UFC} / \mathrm{cm}^{2}$ e dos tratados de $0,003 \mathrm{UFC} / \mathrm{cm}^{2}$, indicando que o tratamento surtiu em reduções decimais num fator superior a 3 .

O ozônio promoveu a negativação das análises de coliformes totais e E. coli (Tabela 1). Os testes para Pseudomonas spp. também foram negativados e observou-se a redução da positividade para S. aureus em $86,7 \%$ das amostras (Tabela 2).

TABELA 1. Contagem total de aeróbios mesófilos, coliformes totais e E. coli, de amostras de galões com e sem tratamento com água ozonizada.

\begin{tabular}{lcc}
\hline \multicolumn{1}{c}{ Microrganismos } & $\begin{array}{c}\text { Pré-lavagem }(\mathrm{N}=30) \\
(\text { sem tratamento) } \\
\text { Média }\end{array}$ & $\begin{array}{c}\text { Pós- lavagem }(\mathrm{N}=30) \\
\text { (tratados) } \\
\text { Média }\end{array}$ \\
\hline Aeróbios Mesófilos $(\mathrm{UFC} / \mathrm{mL})$ & 21,6 & 0,013 \\
Coliformes totais $(\mathrm{NMP} / 100 \mathrm{~mL})$ & 192,53 & - \\
E.coli $(\mathrm{NMP} / 100 \mathrm{~mL})$ & 69,62 & - \\
\hline
\end{tabular}

(-): menor que o limite de detecção do teste utilizado: <1NMP/100mL.

TABELA 2. Pseudomonas spp. e Staphylococcus aureus em amostras de galões de 20L de água mineral, tratados e não tratados com água ozonizada.

\begin{tabular}{lcc}
\hline \multicolumn{1}{c}{ Microrganismos } & $\begin{array}{c}\text { Pré-lavagem ( } \mathrm{N}=30) \\
(\% \text { de amostras positivas })\end{array}$ & $\begin{array}{c}\text { Pós- lavagem }(\mathrm{N}=30) \\
(\% \text { de amostras positivas })\end{array}$ \\
\hline Pseudomonas spp & 50 & - \\
S. aureus & 100 & 13,3 \\
\hline (-): não detectado & &
\end{tabular}

Ressalta-se ainda que o sistema proposto promoveu um tempo de contato de $2 \mathrm{~min}$. da água ozonizada, a uma concentração de aproximadamente $4 \mathrm{mg} / \mathrm{L}$. Em condições experimentais, RESTAINO et al. [10] utilizaram a adição de matéria orgânica na concentração de $0,19 \mathrm{mg} /$ L, e promoveram a inativação instantânea de mais de 5 logs do número de UFC de E.coli. Conseqüentemente existe a possibilidade da redução do tempo de contato e da concentração utilizados neste trabalho, tornando o sistema mais rápido e vantajoso.

\section{4 - CONCLUSÕES}

A utilização do ozônio $(4 \mathrm{mg} / \mathrm{L})$ para a sanificação de galões de $20 \mathrm{~L}$ de água mineral mostrou-se uma alternativa eficiente, nas condições testadas.

\section{5 - REFERÊNCIAS}

[1] ASSOCIAÇÃO BRASILEIRA DAS EMPRESAS DE REFEIÇÕES COLETIVAS (ABERC). Manual Aberc de práticas de elaboração e serviço de refeições para coletividades. 5 ed. São Paulo, 1999.

[2] AMERICAN PUBLIC HEALTH ASSOCIATION. Standards methods for the examination of dairy products. 14 ed. Washington, 1978.

[3] ANDRADE, N.J.; MACÊDO, J. A. de B. Higienização na indústria de alimentos. 1 ed. São Paulo: Varela, 1996.

[4] BLOCK, S.S. DISINFECTION, STERILIZATION AND PRESERVATION. 4. ED. PHILADELPHIA, PA: LEA \& FEBIGER, 1991. 1162P.

[5] BRASIL, Ministério da Saúde. Resolução no 310, de 16 de julho de 1999. Regulamento técnico referente a Padrões de Identidade e qualidade para água mineral natural e água natural. Revista Água Mineral, ago/out, 1999.

[6] GRAHAM, D.M. Use of ozone for food processing. Food Technology, v.6, n.51, p.72-75, 1997.

[7] MARQUES, M. A força das águas. Revista ISTO É, São Paulo. n. 1597, 10 jul. 2000.

[8] PELCZAR JR, M.J; CHAN, E.C.S.; KRIEG, N.R. Microbiologia de alimentos. In: Microbiologia Conceitos e Aplicações. 2 ed., 1996. p.372-387.

[9] PINHEIRO, A.J.R.; MOSQUIM, M.C.A.V.; PINHEIRO, M.I. Processamento de leite de consumo. Rio de Janeiro: CCPL - UFV, 1978. p. 183.

[10] RESTAINO, L.; FRAMPTON, E.W.; HEMPFILL, J.B.; PALNIKAR, P. Efficacy of ozonated water against various food-related microorganisms. Applied. Environm. Microbiol. v.61, n.9, p.3471-3475, 1995.

[11] RICE, R.G. Application of ozone in water and wastewater treatment. In: Analytical aspects of ozone: treatment of water and wastewater. Edited by R.G. Rice, et.al. Chelsea, MI, Lewis Publishers, 1986. p. 7-26.

[12] RICHARDSON, S.D.; TRHUSTON Jr., A.D.; CAUGRHAN, T.V.; COLLETTE, T.W. PATTERSON, K.S.; LYKINS Jr., B.W. Chemical By-Products of chlorine and Alternative Disinfectants. Food Technology: v.52, n.4, p.58-61. apr., 1998.

[13] SPECK, M.L. Compendium of methods for microbiological examination of food. 2.ed. Washington: APHA, 1984.

[14] TORRES, E.A.F.S; REGÊ FERREIRA, A.F; RÍMOLI, C. D. Estudo das propriedades desinfetantes do ozônio em alimentos. Higiene Alimentar, v.10, n.42, p.18-23, 1996.

[15] KURT GIECK. Manual de fórmulas técnicas. 2ed. São Paulo Hemus, 1979. 